Investigations into allergic hypersensitivity in man to Aspergillus fumigatus were described by $\mathbf{J}$. Pepys, R. W. Riddell, K. M. Citron, Y. M. Clayton and E. I. Short. Allergic reactions to the ubiquitous and perennial spores of $A$. fumigatus consist of rhinitis, conjunctivitis and asthma. The fungus also causes respiratory infections, associated with pulmonary eosinophilia, consisting of transient, recurrent pulmonary infiltrations, febrile episodes and eosinophilia of the sputum and blood. A. fumigatus is found with a significantly greater statistical frequency in the sputum of asthmatics without pulmonary eosinophilia than in the sputum of patients with other respiratory disorders.

Hypersensitivity as the cause of the pulmonary eosinophilia was investigated. Skin-prick tests with extracts of $A$. fumigatus, flavus, nidulans, niger and terreus gave positive reactions to almost all species in nearly every hypersensitive subject. Culturemedium filtrates, one month old, were the most potent allergens, followed by the cell sap of fresh mycelia, and then by conventional carbol saline extracts of dried mycelium.

Prick tests produced immediate weal-reactions, followed after 3-12 hr. in a number of cases by a 'late' reaction. This reaction was occasionally quite extensive and differed macroscopically and in its more rapid appearance and resolution from the delayed tuberculin type of reaction. Histologically it showed early, intense and persistent infiltration of eosinophile cells, as compared with the perivascular infiltration of round cells in the tuberculin reaction. These features and the demonstration of precipitating antibodies in the serum of pationts by means of concentrated extracts of Aspergillus, especially $A$. fumigatus, suggest that the 'late' reaction is of the Arthus type.

Bronchial reactions to inhalation tests with extracts of Aspergillus were most evident in patients with pulmonary eosinophilia. Proof that the fungus plays a part in the clinical picture must rest, how. ever, not only on evidence of its presence in the sputum, but also on immunological confirmation.
Preliminary investigations into the immunochemistry of Cladosporium were reported by $\mathrm{J}$. Longbottom, B. Hayward and R. Augustin. Extracts of spores and mycelium were found to be equal in potency in skin tests. Their active components were found, as with pollen, to be nondialysable and to be associated with the protein-like material which did not move from the base-line in paper chromatography.

At least eight antigens were demonstrable in agar-gel tests with rabbit antisera to $C$. fulvum and $C$. herbarum. Antiserum to $C$. herbarum gave precipitation lines with the antigens of $C$. fulvum, but not vice versa. The Cladosporium antigens have the mobilities of serum albumins and $\alpha$ - and $\beta$-globulins. Of four antigens shown by immunoelectrophoresis in $C$. fulvum, three were found to be non-allergenic in man. Patients tested with the extracts and with proteolytic digests of the two species showed individual variations, as might be expected.

J. F. Ackroyd discussed a patient with allergic thrombocytopenic purpura due to antazoline. Antazoline added to the serum caused lysis of the platelets and the formation of a precipitate, both mediated by the same antibody. Taking the drug on two later occasions resulted in a rise in the fallen antibody titre. Formation of a precipitate at these times was not, as it had been previously, accompanied by complement fixation; and no cause could be found for this.

The observation that the formation of a precipitate with complement fixation was produced by adding the drug to serum, collected while the patient was taking sufficient antazoline to give high enough blood-levels to excite thrombocytopenia, suggests that the union of the drug and the platelets is very labile. This dissociability may explain why so fow persons develop purpura on taking antazoline and other drugs such as sedormid, quinine and quinidine, for which a similar lability has been observed.

J. Pepys

\title{
THE NEW FERODO RESEARCH LABORATORIES
}

\author{
BY DR R. C. PARKER
}

Research Director

$\mathrm{O}^{\mathrm{N}}$ November 21, some sixty-one years after $\mathrm{Mr}$. Herbert Frood, the founder of Ferodo Ltd., produced his first friction material, H.R.H. the Duke of Edinburgh formally opened the new Research Laboratories of the firm by unveiling a suitably inscribed bronze plaque. Work on current problems was afterwards inspected. In the following week a series of open days were arranged, one of which was reserved for the teaching staffs of universities, Iocal technical colleges and schools and for the staffs of research institutes.

The building (Fig. 1) is in the form of a splayed $E$ having a total floor area of $75,000 \mathrm{sq}$. $\mathrm{ft}$. The upper two stories of the front of the building house the Administration Department, a Plant Development Department and offices for senior managers, while the two-storied centre wing with a floor area of
12,000 sq. ft. houses the Physical, Chemical and Metallurgical Laboratories. All the internal partitions in both laboratories and offices are built on a five-foot module and can be readily mounted or removed as desired. The left-hand wing, covering 21,000 sq. ft., comprises an Engineering Test House, a workshop and a test car garage, and the right-hand wing, with an area of 18,000 sq. ft., contains pilot plant. The site of the building is such that when further space is required the length of the three projecting wings can be increased by 50 per cent. The building is pleasantly situated on the main road from Chapelen-le-Frith to Hayfield, and is set among landscape gardens.

The main heating of the offices and the laboratories is by warm water that circulates through special steel coils embedded in the ceilings. Supplementirg 


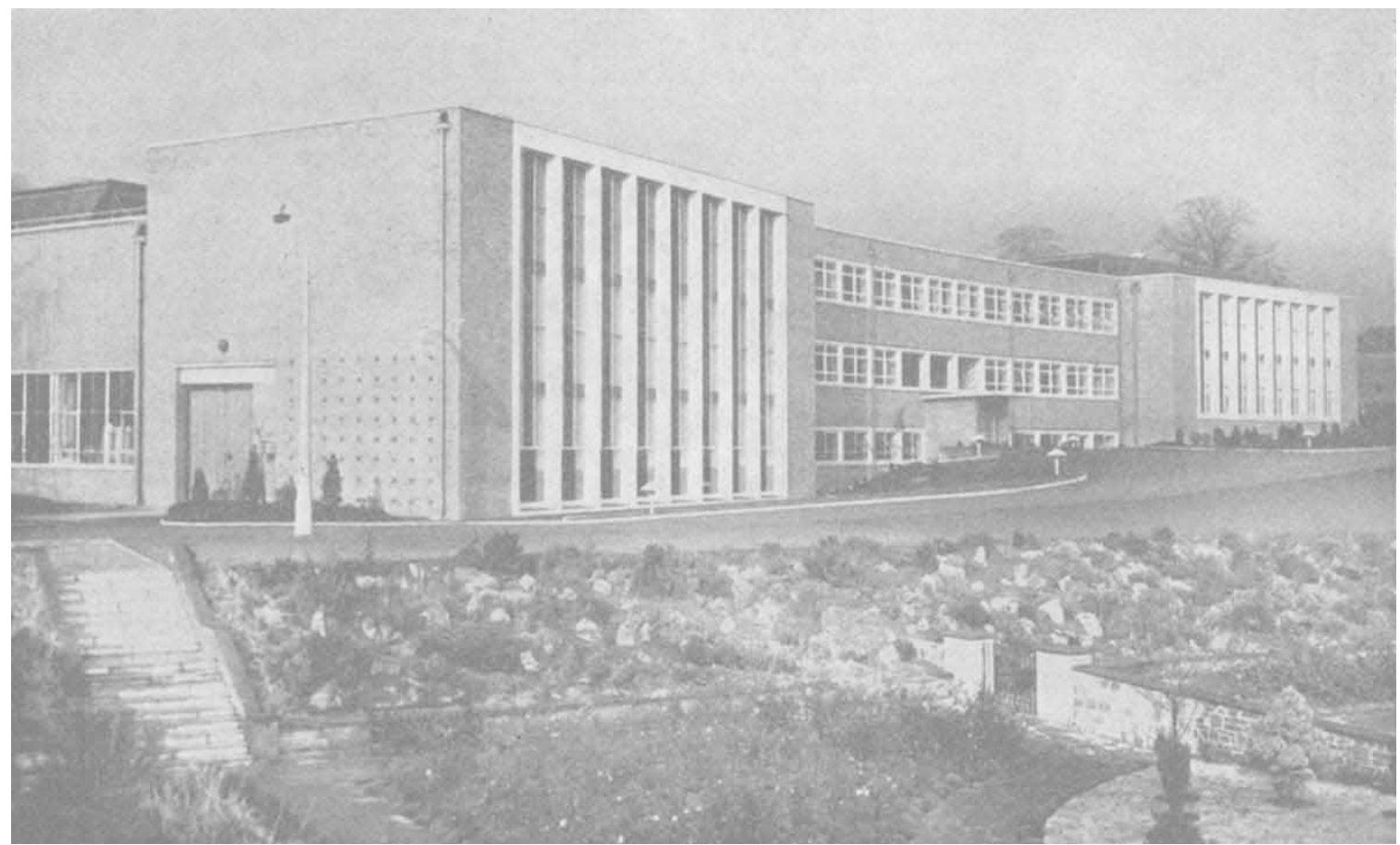

Fig. 1. The new Ferodo Research Laboratories at Chapel-en-le-Frith

this is warm filtered air which is led into each five-foot module, and afterwards extraction is by a fan system so designed that the air in each room is changed from four to five times every hour. The two outer wings are heated by unit heaters of the down-sitream type fixed high in the roof and controlled by thermostats fixed at working level. Ventilation of these outer wings is by means of fresh-air ducts connected to the unit heaters and by extraction fans in the roof. In addition to gas, hot and cold water is provided, together with the usual electrical services. Steam is provided at $180 \mathrm{lb} . / \mathrm{sq}$. in. and at $40 \mathrm{lb} . / \mathrm{sq}$. in., and compressed air at $100 \mathrm{lb} . / \mathrm{sq}$. in. All services to the laboratories are housed in timber ducts that run along the walls from window-sill-level to floor-level. Services to island benches are accommodated beneath the timber and reinforced concrete floor.

The laboratories are lit by 80 -watt fluorescent tubes in fittings on the ceilings, giving an average value of illumination of about 30 lumens per sq. ft. at desklevel. The Test House and Experimontal Production Laboratory are lit by 250-watt mercury vapour lamps and 500-watt tungsten filament lamps which give an illumination of some 18 lumens por sq. $\mathrm{ft}$.

The research and development programmes carried out in the new building are all directed towards the production of improved types of friction material for the automotive industry and for railways, aviation, mining and indeed every industry that employs moving machinery. Almost irrespective of the application, demands on friction materials are ever increasing both in number and intensity, and in the case of automotive brakes, for example, the peak energy dissipation per unit area has more than doubled within the past decade. Attention has not only to be given to the level of friction under varying conditions of pressure, speed, temperature and surface roughnoss, but also to durability, squeal, oil resistance, water resistance and many other such factors.
In order to be able to produce durable material with the required value of friction, research in the laboratories is carried out along many inter-related channels. Long-term work is carried out on the mechanism of friction and wear, and this involves the study of the bulk and surface properties of a wide range of different materials. Next, basic work of a medium-term nature follows on the friction materials themselves, and this has, as one of its objects, the further study of certain aspects of behaviour to which the long-term programme has directed attention. The third, last and most important link in the chain is the development of new friction materials to solve immediate problems, a process which, though continually eased by the flow of knowledge from the longer-term programmes, nevertheless derives a great deal from intuition and past experience. In parallel with this work on friction and wear, detailed researches are carried out on the properties of the more important raw materials. Asbestos is a particularly important material since, being a fibrous inorganic mineral, it is associated with three essential properties, namely, heat resistance, strength and flexibility. Studies on this mineral are being carried out by means of $\mathrm{X}$-ray diffraction, electron microscopy and other techniques, and the structure of chrysotile and one of the amphiboles, namely, Bolivian crocidolite, has been elucidated. The investigations are run parallel with work on other properties of asbestos in order to obtain the clearest understanding of its many important characteristics. Investigations are also made of natural oils and resins by means of infra-red spectroscopy and liquid and gas chromatography, not only with the object of seeking a correlation between their properties and the friction and wear of the final product, but also to ensure that when complex mixes are involved, the components can be identified so that the activity of the oils can be maintained constant by a suitable system of blending. Mechanical investigations are used to examine the 
No 4657 January 31, 1959

behaviour of the many different types of brakes and to record the conditions to which they are subjected in service. Surface temperature is one of the many important variables, and both its measurement and calculation are of vital importance.

The Test House contains test dynamometers of the inertia type for examining experimental materials under conditions that can be encountered in service. The machines are, in the main, automatic in operation and are self-recording, and permit a much closer control and therefore a better opportunity for studying the various factors affecting behaviour. The larger machines are designed to fit the types of brakes used on aircraft, heavy transport, railways and industrial brakes, while on the smaller machines provision is made to fit brakes varying from automotive to bicycle. The workshop adjoining the Test House is fully equipped to make all but the large parts of the various test machines, and the laboratories situated on a second floor over the workshop and test car garage are concerned with the design and construction of the various servo and other devices needed for the operation and control of the machines. Towards the end of the wing is a test car garage which houses a fleet of test vehicles, including motorcycles, large and small saloon cars, high-performance sports cars, lorries and buses. The vehicles are all fitted with instruments of various types which, in effect, make them mobile laboratories.
Although the laboratories stand adjacent to the factory, it was considered essential for them to be self-contained, and to this end the pilot-plant laboratory is equipped with all the production plant and finishing apparatus required to make prototype materials. Such provision not only enables development staff to plan their work more easily, but also frees production plant in the factory from costly interruptions. One section of this wing is allocated to the Production Plant Development Section, which carries out all the proving trials that may be necessary on new plant of a novel design. This design section works not only in close co-operation with the pilot plant section, but also with those chemists and physicists who are concerned with ideas still only in their embryonic stage.

Even this brief description of the laboratories should serve to show that the study of friction and the manufacture of friction materials involves contributions from chemists, engineers, metallurgists, mathematicians, statisticians, physicists and physical chemists. Indeed, the added interest gained from co-operating with so many different disciplines serves to render a fascinating study exhilarating.

The architects for the new Ferodo Research Laboratories were Messrs. Ashworth and Fletcher; the quantity surveyors Messrs. Worrell and Kelly; and the consulting engineers Messrs. R. W. Gregory and Partners.

\section{THE SCIENCE MASTERS' ASSOCIATION}

\section{ANNUAL MEETING}

$\mathrm{T}$ 'HE annual meeting of the Science Masters' Association was held in University College and Queen Elizabeth College, London, during December 30-January 2, and was attended by a thousand members and many guests; this number included members from Canada, India, Pakistan, South and West Africa, and the United States. Among them was Prof. R. W. Lefler, of Purdue University, Indiana, who is at present acting as adviser in physics to the Nationalist University in Formosa.

The meeting began with the presidential address by Sir Lawrence Bragg, who outlined the past history and present policy of the Royal Institution. The second evening was occupied by a lecture by Dr. $\mathrm{H}$. Lister on the recent Trans-Antarctic Expedition; this was notable for the splendid coloured slides.

The programme of morning lectures by members of the staff of University College, together with guest lecturers from Harwell, the Brunel College of Technology, the London Institute of Education, and Woodberry Down School, London, has already been given in Nature (December 6, p. 1554). One of these, that by Mr. H. G. Conway, of Short Brothers and Harland, Belfast, on "New Engineering Problems in Aeronautics", was attended by Air Marshal Sir Owen Jones, president of the Institution of Mechanical Engineers, and other members of the Institution.

The Manufacturers' and Publishers' Exhibitions, held in University College, were larger than ever before, with the result that the exhibition of apparatus and other items brought by members had to be housed in Queen Elizabeth College. Among these exhibits was an intensely interesting historic one, namely,
Faraday's bible, shown by Mr. E. H. Duckworth, of Cheltenham; this contained Faraday's autograph and his original marking of important texts.

The Science and Religion Group was addressed by the Rev. Aubrey Vine, general secretary of the Free Church Federal Council.

An innovation was the organization, at the suggestion of Mr. D. G. Chisman, education officer of the Royal Institute of Chemistry, of evening receptions by that Institute and by the Institutes of Physics and of Biology. These were much appreciated by members, as was shown by the fact that applications to attend far exceeded the available accommoda. tion. The afternoons were occupied by visits to university departments and to factories in or near London; for other members there were exhibitions of scientific films.

At the business meeting of the Association $\mathrm{Mr}$. D. G. James, vice-chancellor of the University of Southampton, was elected president for the ensuing year : Dr. H. F. Boulind, of the University of Cam. bridge Department of Education, was elected chairman, and Mr. H. Lockett, of Taunton's School, Southampton, became the new annual meeting secretary. It was announced that a summer meeting would be held, during July 28-31, in the Durham Colleges of the University of Durham. The next annual meeting will be in the University of Southampton, during December 29-January 1, 1960.

The second half of the business meeting was occupied with the discussion of a resolution, moved by Mr. D. N. Underwood and Mr. E. Chanter, which read : "that this meeting disapproves of the contin- 